\title{
Integrated and comprehensive estimation of greenhouse gas emissions from land systems
}

\author{
Cris Brack · Gary Richards · Robert Waterworth
}

Received: 14 February 2006/ Accepted: 29 May 2006/ Published online: 19 September 2006

(C) Integrated Research System for Sustainability Science and Springer-Verlag 2006

\begin{abstract}
Exchanges of carbon and nitrogen between the atmosphere and terrestrial ecosystems involve a complex set of interactions affected by both natural and management processes. Understanding these processes is important for managing ecosystem productivity and sustainability. Management processes also affect the net outcome of exchanges of greenhouse gases between terrestrial ecosystems and the atmosphere. In developing a national carbon accounting system (NCAS) for Australia to account for emissions and removal of greenhouse gases to and from the atmosphere, a carbon:nitrogen mass balance ecosystem model (FullCAM) was developed. The FullCAM model is a hybrid of empirical and process modelling. The approach enables application to a wide range of natural resource management issues, because it is at land-management-relevant spatial and temporal resolution and captures the main process and management drivers. The scenario-prediction capability can be used to determine the emissions consequences of different management activities. Because, in Australia, emissions
\end{abstract}

C. Brack $(\bowtie) \cdot$ G. Richards $\cdot$ R. Waterworth

School of Resources, Environment and Society,

Australian National University,

Acton, ACT, Australia 0200

e-mail: cris.brack@anu.edu.au

G. Richards $\cdot$ R. Waterworth

Department of Environment and Heritage,

National Carbon Accounting System,

Australian Greenhouse Office, GPO Box 787,

Canberra, ACT, Australia 2601

C. Brack $\cdot$ R. Waterworth

Cooperative Research Centre for Greenhouse Accounting,

GPO Box 475, Canberra, ACT, Australia 2601 of greenhouse gases are closely related to the retention of dead organic matter and the availability of nitrogen for plant growth, the carbon and nitrogen cycling as modelled are good indicators of ecosystem productivity and condition. The NCAS also emphasizes the advantages of a comprehensive and integrated approach to developing a continental scale ecosystem-modelling system that has relevance both to estimation of greenhouse gas emissions and sustainable management of natural resources.

Keywords Carbon $\cdot$ Nitrogen $\cdot$ Ecosystem modelling · FullCAM $\cdot$ NCAS

\section{Introduction}

Lund and Iremonger (2000) conclude that nearly "all natural resource issues, whether they are environmental, social, economic, ecological or political, are national as well as global issues". The quantification and management of greenhouse gas emissions is an obvious issue of significance at both national and global levels (IPCC 2001). Lund and Iremonger (2000) also warn that acquiring an integrated national or global understanding of natural resources is extremely problematic, because current inventory approaches tend to include significant errors of omission and commission. To ensure that all forest and non-forest land is accounted for it is necessary to integrate data-collection efforts over all lands and resources, irrespective of land use.

In addition to covering all lands, inventory approaches must cover all relevant ecosystem components. For monitoring and managing greenhouse gas 
emissions, this must consider all relevant carbon pools; biomass, dead organic matter, and soil. Because both carbon and nitrogen move between these different ecosystem pools, integration of data over all pools is required for a comprehensive inventory of greenhouse gas emissions. Forest and agricultural biomass (above and below ground), soil carbon, litter and debris, and off-site material (e.g. wood products) are the major pools for carbon, and each has the potential to be either a source or sink of greenhouse gases.

To develop a comprehensive system to report on Australia's land-based greenhouse gas emissions and removals (from and to the atmosphere) the national carbon accounting system (NCAS) was formed. The NCAS enables comprehensive estimation of emissions for Australia's international reporting obligations and supports national policy development. The NCAS integrates a wide range of spatially referenced data by means of a hybrid of process and empirical models that estimate carbon stock change and greenhouse gas emissions at fine spatial and temporal resolution. Analysis and reporting includes all carbon pools and all principal greenhouse gases $\left(\mathrm{CO}_{2}, \mathrm{CH}_{4}\right.$, and $\left.\mathrm{N}_{2} \mathrm{O}\right)$, and can be applied on a variety of scales, from the project level to regional and continental levels, covering both forest and agricultural land use.

NCAS was specifically challenged to be relevant both to annual national reporting and to supporting location-specific management actions. The resulting need to operate at fine temporal and spatial resolution, for management relevance, led to a bottom-up approach of aggregating $25 \mathrm{~m}$ grid resolution data and modelling into a national account. Although the landcover change data (the principal driver) and modelling are performed at $25 \mathrm{~m}$ resolution, not all data are available or needed on this fine scale for the bottom-up approach to be effective. A top-down approach to forming the national account with a relatively large sample over the entire continent could not provide sufficient samples or resolution to support site-specific management decisions or enable project-level estimates.

The terrestrial ecosystem model implemented by the NCAS is the full carbon accounting model (FullCAM) (Richards 2001; Richards and Evans 2004). FullCAM is a carbon:nitrogen (C:N) ratio ecosystem model that calculates greenhouse gas emissions and removals for both forest and agricultural land using a mass balance approach to carbon and nitrogen cycling. Because most land-based emissions and removals of greenhouse gases in Australia occur on transition between forest and agricultural land-use, integration of agricultural and forestry modelling was essential. Model calibration and ongoing refinement programs are completed in parallel with the NCAS science and data-collection programs and reporting activity.

The continental spatial and temporal modelling capabilities of FullCAM help prevent errors of omission and commission. FullCAM also forms the basis of the publicly available national carbon accounting toolbox (NCAT) which enables users to develop project-level carbon accounts using the same data as used for deriving national accounts, achieving consistency between national and project level accounting activity.

Although specifically developed to estimate greenhouse gas emissions, the FullCAM model and NCAS data have the potential to serve as a valuable framework for a range of land resource inventory and monitoring tasks. The national scale, fine spatial and temporal resolution, and breadth of data (climate, soils, productivity, land cover, and management information) provide a comprehensive data and modelling capability not previously available in a single system. This paper reviews the ongoing development of FullCAM and NCAS, and presents some verification and validation results. Particular attention is paid to the novel approach of forest growth modelling.

\section{Methods}

\section{Method selection}

Several possible methods were available for development of the NCAS. These included direct measurement via a range of remote sensing techniques (e.g. optical, radar and lidar sensors), field sampling (e.g. stratified random or plot sampling inventory approaches), process modelling, or integration of methods (e.g. combination of models, inventory data and remote sensing).

The method chosen was an integrated approach using remote sensing, empirical, and process models. Landsat images are used to determine changes in land cover. A hybrid of verified empirical and process models are used to estimate the cycling of carbon and nitrogen in plant biomass, dead organic matter, soils and offsite products and the emission and removal of greenhouse gases.

Because the primary concern was understanding the effect of changes in land cover and land use on greenhouse gas emissions, the modelling framework was designed to accommodate both forest and agricultural land use, and any transitions between them. The model framework was fully integrated so that mass balance checks could be performed to ensure that all 
inputs, transfers, and emissions were properly reconciled at each time step in the calculation.

A purely measurement approach to developing the NCAS would probably have provided a robust national account, but potentially at greater cost than the model approach chosen. A measurement approach would not have supported analysis of either project level estimates, however, or supported management decision making. The process understanding generated by use of models enables the development of management practices and land-use policies for which estimated outcomes are reliable. Having such capacity is fundamental to cost-benefit analysis of mitigation actions and for optimising outcomes for multiple goals (e.g. maintaining production while reducing emissions).

\section{Model development}

The development of the FullCAM model started with the "point-based" carbon accounting model for forests (CAMFor) (Richards and Evans 2000a), which was based on the $\mathrm{CO}_{2}$ Fix model (Mohren and Goldewik 1990). CAMFor primarily focussed on carbon sequestration in trees using basic species information and standard forestry yield tables entered by the user, with limited debris and soil carbon modelling capabilities. After the successful development and testing of CAMFor the carbon accounting model for agriculture (CAMAg), was developed to perform similar functions to CAMFor, but for agricultural systems (Richards and Evans 2000b).

To enable more complete carbon modelling CAMFor was integrated with several existing models; RothC for soil carbon (Jenkinson 1990), GENDEC for litter decomposition (Moorehead and Reynolds 1991) and 3PG for tree growth (Landsberg and Waring 1997) to form the full carbon accounting model (FullCAM). Other model components, for example the GORCAM bioenergy and product displacement model of Schlamadinger et al. (1997), were also included and a nitrogen cycling capability based on the Century model (Parton et al. 1987) and the boundary layer approach (Conen et al. 2000) were added to enable estimation of emissions of nitrous oxide.

The model is internally duplicated, enabling parallel, but independent, calibration and running of the agricultural and forest systems, and transitions between these land-use systems. Integration of the agricultural and forest models helps ensure conservation of mass during carbon and nitrogen cycling by including all pools and transfers between pools, thus ensuring there are no significant instances of double counting or omissions in accounting. Deforestation at one point, for example, uses the forest model components to estimate the continuing decay and emission of carbon from dead wood, litter, off-site, and soil pools whereas the agricultural model components estimate the changes in pools that result from introduction of agricultural inputs. This recognises the different cycling rates in the different biomass inputs. The model can report results from any pool or land use, or sum all the results into a single estimate of carbon stock. FullCAM can be linked to spatial data and run as a grid-based application in addition to its point-based application.

\section{Data sources}

Initial tasks were to gather all the available data, review its utility, combine data of different origins, and report the methods and outputs in a series of technical reports. The NCAS Technical Report Series (http:// www.greenhouse.gov.au/ncas; ISSN: 1442 6836) also covers model development and calibration, and a variety of verification activity. Available national data, for example the vegetation groups of the National Vegetation Information System (NLWRA 2001) were used where available. Where such national compilations were not available, e.g. on soil carbon content and clay content, national collation and combination of available inventory and research data were undertaken (Skjemstad et al. 2000; Webbnet Land Resource Services 2002).

\section{Climate}

Climate variation has a significant effect on emissions in the short term and, because many management and reporting issues also relate to short term changes, it is important to be able to account for this variability. The process-based models used in FullCAM (3-PG, RothC, GENDEC) can use appropriate climate data to reflect this variability. The NCAS has developed monthly climate grids from 1968 to 2004 for rainfall, minimum, average, and maximum temperature, evaporation, vapour pressure deficit, and frost (Kesteven et al. 2004). This climate data is updated as new data become available.

\section{Land cover change}

The importance of land cover change to the pattern of greenhouse gas emission and removal led to the need to develop a national time series of land-cover change showing both where and when change occurs. National coverages of Landsat satellite data (MSS, TM, and 
$\mathrm{ETM}^{+}$) across fourteen time epochs from 1972 to 2005 have been assembled and analysed for change (Caccetta et al. 2003). The historic cover and cover change information is important in two ways. First, the effects on greenhouse gas emissions from land cover change are typically long-lasting, and historic activities may still contribute to current estimates. Second, emission and removal by current activity will be affected by site history. For example, a current deforestation event will probably generate fewer emissions if the forest cleared is secondary forest (regrowth after a previous deforestation) rather than a primary (mature) forest.

Individual vegetation species characteristics, management practices, and general growth information have also been collated into a set of databases. The databases are relational, i.e. spatially referenced on the basis of set regions (e.g. the interim-biographical regions of Australia (Thackway and Cresswell 1995)) with changes in management varying over time and with species. Historic information on both forest and agricultural management systems was obtained from experts and documented in a variety of technical reports (Swift and Skjemstad 2002; Squire and Raison 2006).

\section{Crop yield}

Crop yields are used in the model to determine several factors in the model calibration. In almost all instances where crop yields are used, their impact on carbon and nitrogen cycling is determined in concert with the management approach applied. The uses of the crop yield information include:

- determining plant biomass (crop or grass) at a point in time, by use of "harvest indices" that relate total plant biomass to the yield commodity of interest (e.g. grain);

- determining how much plant biomass is removed from the site as product;

- determining the amount of root slough as input to soil from plant growth coupled with management practices; and

- determining the post harvest/grazing resides burnt, decomposed on soil surface or incorporated into soil.

Data on crop yield and management practice are jointly collected because management practices will determine the crop yields and the fate of crop residues. Initial data collection from 1970 onwards is supplemented annually. Data are drawn from a variety of sources including statistical and industry holdings, crop-growth modelling, and expert opinion. One of the planned future developments in the modelling framework will be to incorporate generic crop and pasture yield models into FullCAM. Initial testing indicates that this can be achieved by use of a small number of generic model types for broad crop classes.

\section{Forest growth}

Providing a dynamic, disturbance, and managementresponsive forest growth model for all of Australia's forests was particularly challenging. The novel spatial modelling approach eventually used combines the strengths of both empirical and processed based modelling.

The forest-growth model component of FullCAM can be described either as a hybrid of process and empirical modelling or as an empirically constrained process model. In this system process models estimate the relative movements between pools and account for climatic variability while empirical data set calibration constraints. The empirical data that constrain the model reflect extensive field data (both already available and specifically collected). Independent data was used to verify the model application (Harms and Dalal 2002; Griffin et al. 2002; Murphy et al. 2002; Raison et al. 2003).

Site and climate data are used in a simple processbased model (a simplified version of 3PG spatial) to develop continental estimates of productivity (Kesteven et al. 2004). The 3-PG variant used is a truncated version of the full 3-PG model (Landsberg and Waring 1997; Sands and Landsberg 2002), retaining the essential features of net primary productivity estimation, without species-specific growth information or the carbon-partitioning algorithms (Eq. 1). This variant of the model provides a time series of the site productivity index $(P)$ ranging from 1 (low) to 30 (high). The longterm average productivity defines long-term potential biomass accumulation whereas monthly productivity values provide a relative temporal productivity estimate at each point.

The essence of this model is calculation of the amount of photosynthetically active radiation (APAR) absorbed by plant canopies. The factor converting APAR to biomass is reduced from the selected optimum value by modifiers depending on soil fertility, atmospheric vapour pressure deficits, soil water content, and temperature:

$\mathrm{P}=\mathrm{APAR} \times \mathrm{T} \times \mathrm{S} \times \mathrm{W} \times 0.01 \times(1-\mathrm{F})$,

where: $P$ denotes the productivity index; 
$T$ denotes a variable between 0 and 1 that reduces the potential $P$ if the monthly temperature deviates substantially from a range of temperatures;

$S$ denotes a level of fertility (high, medium and low); these levels are applied for each pixel, depending on soil type, before environmental modifiers are applied;

$W$ denotes a variable between 0 and 1 which is calculated from the most limiting factor of soil water content or vapour pressure deficit; and

$F$ denotes the ratio of the number of frost days per month to the number of days in the month.

$P$ is developed for each point over a continental grid using:

- Monthly climate surfaces developed for the NCAS (Kesteven et al. 2004);

- CSIRO's national soil moisture-holding capacity and fertility mapping (McKenzie et al. 2000);

- The $9 \mathrm{~s}(250 \mathrm{~m})$ Digital Elevation Mapping Version 2.0 (AUSLIG 2001); and

- Normalised difference vegetation index (NDVI) data of the Environmental Resources Information Network (ERIN).

Long-term average $P$ values were then correlated to verified and spatially referenced observations of aboveground biomass in undisturbed forest stands at or near maturity. These biomass data were collated by means of an extensive search of published and unpublished CSIRO data and ranged from arid shrublands $\left(2 \mathrm{t} \mathrm{ha}^{-1}\right)$ to tall wet sclerophyll forests $\left(900 \mathrm{t} \mathrm{ha}^{-1}\right.$ ) (Raison et al. 2003). The relationship between mass and long-term average productivity was then used to derive a map of potential site biomass at maturity (i.e. for long-term undisturbed stands). Model calibration is discussed in the section Forest growth, below.

\section{Management data}

Land-management practices in both agriculture and forestry in Australia have varied substantially over time, depending on species, region, desired products, and site conditions. There were, however, no consistent, nationally available compilations of this information and separate programs to compile the needed information were undertaken. Although there was no overlap between the forest and agricultural management data programs, the methods used were similar. In both instances a focus group comprising researchers and practitioners was established to give all management issues (e.g. forest and crop type, burning, harvesting, thinning) jurisdictional (geographic) and temporal coverage. All available information was collated and supplemented with expert knowledge to achieve completeness where records were not available. The information gathered by these groups for use in the management databases is documented in Swift and Skjemstad (2002) and Squire and Raison (2006).

Databases were constructed for relevant geographic regions, further stratified spatially by relevant characteristics, for example soil and forest type, then classified in accordance with final non-spatial strata, for example crop type or tree species. Management systems for each sub-region were then defined as bundles of practices that represented typical management regimes. Each regime was then apportioned to the finest spatial stratification, giving relative frequencies of implementation for available regimes that could vary over time. The resulting databases cover a large range of possible scenarios with over 5,000 regimes, each comprising 10-30 specific practices, developed for plantation forests alone. The databases were developed within FullCAM to enable full integration with NCAS spatial data sources.

Fire plays a significant role in Australia's natural and managed land-based systems. In FullCAM fire is modelled as an event with different characteristics depending on the nature of the event. Fire affects both live plants (i.e. trees and crops) and debris. During a fire each plant pool component (i.e. stem, bark, foliage etc.) is either retained to grow on into the future, emitted to the atmosphere, or becomes debris. Debris is either left unburnt, emitted back atmosphere or transferred to the inert soil pool. The amount of material retained in the plant pools, emitted to the atmosphere, or moved to debris or soil pools depends on the species, and the type and intensity of the fire. Management fires, for example burning for regeneration or residue reduction, are modelled using distinct events within each management system. Wildfires can also be modelled using the same types of event, but with different characteristics, and are not included in standard management systems.

Coarse woody debris and litter

Coarse woody debris and forest floor litter are particularly difficult to estimate using measurement techniques because they are highly variable and dynamically related to forest productivity and disturbance history (particularly fire and harvest). Data were collected from available literature, but were sparse, particularly for forests without timber harvest. Supplementary data were collected during field sampling (Harms and Dalal 2002; Murphy et al. 2002).

Estimates of coarse woody debris and litter are used to frame the initial model estimates to reflect typical 
species and management scenarios. FullCAM can then be run-in from the initial estimates with inputs to the debris and litter pools based on turnover from live pools (based on the forest-growth model) and the imposition of a known disturbance history (from the land cover change data). This enables conversion of an uncertain historic initial estimate to a site and speciesspecific estimate.

Soils

The application of a spatial modelling approach for changes in soil carbon reduces the ongoing burden of measurement from that of sufficient measurements to estimate change over time across the country to that required for a strategic approach to model verification. Even the application of a model-based approach, however, requires substantial amounts of descriptive and process data. The data requirements can be classed as:

- resource description (maps of soil type, carbon content, clay, etc.);

- ancillary data (land-use, climate, residue inputs, etc.);

- model calibration data; and

- model verification data.

Resource description data are the soil "physical" properties needed for input to the soil-carbon model and include soil type, carbon content (pre-disturbance), and clay content. Maps of these properties were developed by combination of resource inventory data, predominantly available from state governments. Clay content was a consistent measure and relatively easily included in a national model. Soil type descriptions varied according to jurisdiction, but within the modelling framework these differences could be accommodated (Webbnet Land Resource Services 2002).

Substantial additional analytical work was required to achieve consistency of data for pre-disturbance soilcarbon content. This need was primarily derived from the differing analytical techniques used to assess the carbon content of soil samples. To provide a common and consistent national map, archived samples of soil were re-analysed and correction factors to a Leco dry combustion standard were derived (Skjemstad et al. 2000). Fractionation schemes were also derived for partitioning soil carbon into the pool structures used in the soil-carbon model.

Ancillary data inputs to the soil carbon model include information about land use and management, climate, and crop yields (because these affect residue inputs when coupled with management practices). These data have been described in previous sections. The data required for model calibration are characterised by:

- quality and completeness of measurement;

- availability of time-series information; and

- availability of measurements relevant to model variables.

Testing the ability of the models to predict change in other locations on the basis of these calibrations was independently verified by use of an independent measurement program. The verification program needed to measure fewer properties (e.g. total soil carbon change rather than change in fractions) and could therefore be applied to more sites. Calibration data were drawn from a series of both forestry and agricultural research sites. Such sites were sparse, but were ideally suited to the model calibration task having well recorded, comprehensive, and time-series-consistent measurements of key model data.

Model verification used a mix of existing time-series data, and new paired-site comparisons to test model predictions of change. The model calibration and verification results for agriculture can be found in Skjemstad and Spouncer (2002) and for forestry in Paul et al. (2002) and (2003).

\section{Wood products}

When an agricultural or forest system is harvested or thinned, carbon stored on-site in plant or debris material can be moved off-site as a range of products. The amount of time these products take to decay and return their carbon to the atmosphere depends on the species characteristics, type of product, and the amount of movement between product pools. Forest products in particular can provide an important longer-term store of carbon off-site and hence must be taken into account in a full mass balance model. Input data to estimate the flow of material into harvested wood products can be accessed via top-down national statistics (forest production and consumption reporting) or by modelled outputs from forest harvest activities (bottom-up).

The top-down model has been progressively developed (Jaakko Pöyry Consulting 1999, 2000) and has utilised a mix of input statistics from Australia's quarterly forest production and consumption statistics and industry estimates. Data for model calibration (e.g. processing losses, service life, and rates of recycling) have been variously drawn from available literature, industry estimates and expert opinion. For the bottom-up 
approach, FullCAM includes separate product pools for the forest (biofuel, pulp, and paper, packing wood, furniture and poles, fibreboard, construction wood, and mill residue) and agricultural (biofuel, grain, bud and fruit products, cane products, leaf products, root products, hay, straw and silage products, and animal products) aspects of the model. Carbon in the on-site plant or debris pools can be moved to the relevant product pools at any harvest or thinning event. The amount of carbon moved to each product pool is determined by the quantity of carbon on the site, the intensity of the harvest and the desired product splits.

Each product has a different set of in-use decay and bioenergy use properties. Forest products also have transfer to landfill rate and in-landfill decay properties. Decay and transfer rates are modelled exponentially on the basis of percentage of material moved from the pool each year. Individual species can have different sets of product decomposition or transfer properties, enabling different species with different product characteristics to be established over time (e.g. changing plantation species at the end of a rotation) while still tracking all products consistently. Further to the product decomposition modelling, FullCAM also incorporates GORCAM (Schlamadinger et al. 1997), which enables modelling of the displacement of fossil fuel emissions because of use of bioenergy products and displacement because of the use of alternative products. This enables the relative merits of different types of forest and agricultural product to be assessed in comparison with other products that may be used as a substitute. The inclusion of GORCAM enables FullCAM to consider a life-cycle approach in carbon accounting.

\section{Model calibration}

Forest growth

A novel approach has been taken for estimation of forest growth, and is therefore treated here in more detail than other model components. A linear regression (Fig. 1) found a significant correlation $(P<0.01$, $\left.r^{2}=0.68\right)$ between long-term aboveground stand biomass $(M)$ and long-term average forest productivity index (Richards and Brack 2004):

$M=(6.011 \times \sqrt{P}-5.291)^{2}$,

where $P$ is the long-term average forest productivity index and $M$ is the above ground biomass in $\mathrm{t} \mathrm{ha}^{-1}$ dry matter.

\section{$\underline{\text { RothC Model Calibration }}$}

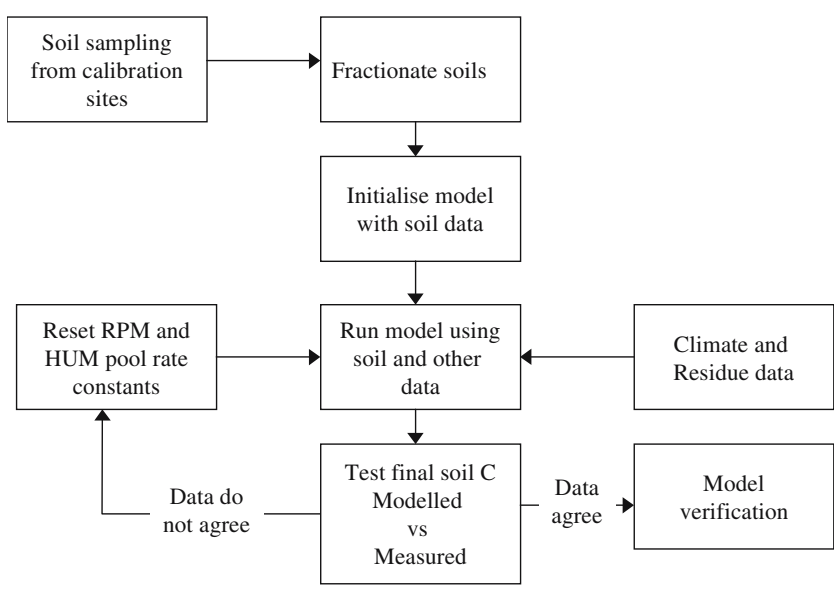

Fig. 1 Procedure for the calibration of the RothC soil component of FullCAM

For forests that have been disturbed (e.g. cleared, harvested, or burnt) and are no longer near $M$ (Eq. 2), a simple mathematical model was developed to enable calculation of standing biomass, given years since disturbance (i.e. age) and the rate at which maximum biomass is approached (Eq. 3).

$M_{\mathrm{A}}=M \times \mathrm{e}^{-k / A}$,

where $M_{\mathrm{A}}$ is the predicted above ground tree biomass ( $\mathrm{t} \mathrm{ha}^{-1}$ ) at age $A$ (years), $M$ is the maximum long-term above-ground tree stand biomass; and $k$ is an estimated constant that determines the rate of approach toward $M$.

Given Eqs. 2 and 3, the long-term average annual increment between $A$ and $A+1$ years $\left(I_{\mathrm{A}}\right)$ for a stand can be estimated from the long-term average productivity $(P)$ :

$$
I_{a}=(6.011 \times \sqrt{P}-5.291)^{2} \times\left(\mathrm{e}^{-k / A}-\mathrm{e}^{-k / A+1}\right) .
$$

Because productivity in any given year may vary around the average, however, because of non-average weather or other factors, the average annual increment may be adjusted by the productivity in a given year $\left(P_{\mathrm{A}}\right)$ as a ratio with the average productivity $(P)$ :

$\bar{I}_{A}=I_{A} \times \frac{P_{A}}{P}$.

Values of $k$ for given species and regime types are available from an extensive spatial database derived from available empirical data. Management intervention 
(forest treatment) can affect the value of $M, k$ or the "relative age" of the trees, however. These treatments can be modelled to advance (or retard) growth for a specified period (Type 1 event, e.g. enabling five years growth in only four years) or increased growth over the entire rotation (Type 2 event, e.g. improve site productivity or change species) as per Snowdon (2002). The hybrid FullCAM forest growth model has been calibrated and adjusted for use in plantation systems based on these Type 1 and 2 responses.

\section{Coarse woody debris and litter}

Carbon and nitrogen from the plant biomass pools is added and lost from the debris pools (deadwood, bark litter, leaf litter, dead coarse roots, dead fine roots) as a result of turnover, mortality or disturbance events, for example harvesting, thinning, fire, ploughing, grazing or herbicide application. Turnover occurs continually from each plant biomass pool (except stems) and depends on the current mass in the pool. The quantity of debris added from each plant biomass pool by disturbance events depends on the type and intensity of the event and the current plant mass.

Plant material moving to debris is divided into resistant and decomposable pools, each with different decomposition rates. On decomposition, some of the stored carbon is released to the atmosphere with the remainder entering the mulch pools, as described below. Decomposing litter moves to the mulch layer, which is in between the debris and the soil. Mulch decomposition is modelled using the GENDEC (GENeral DEComposition) model (Moorehead and Reynolds 1991).

Decomposition rates depend on moisture, temperature and litter "quality" based on the C:N ratio of the mulch pool. Material entering the mulch pool from decomposable debris enters the soluble plant mulch. Material entering from the resistant debris pools can enter either the less-resistant plant mulch or the moreresistant plant mulch pools.

Mulch is either decomposed or humified, moving carbon and nitrogen from the mulch pools to the soil pools. Decomposition occurs as a result of consumption of mulch by soil microbes, thereby passing the carbon back to the atmosphere as emissions or storing it in the bodies of the microbes themselves. The microbes then either excrete the digested mulch or die, turning over their carbon and nitrogen to the soil pools. Humification is the process whereby mulch is moved to the soil pools by the action of more complex soil organisms, for example earthworms or slaters.
Soil

Calibration of the soil carbon model was completed around a structured procedure, as shown in Fig. 1.

The soil carbon turnover model used in FullCAM is an adaptation of the RothC soil carbon model (Jenkinson 1990). The structure of the model is represented in Fig. 2, below.

After investigation of sites that met the requirements for model calibration, two agricultural and seven forestry sites were selected. One agricultural site is on a monsoonal subtropical environment with heavy clay soil and the other is in a temperate Mediterranean climate with a light textured soil. At each agricultural site, soil samples $(0-30 \mathrm{~cm})$ from the beginning and the end of the trial and some in between were fractionated into particulate organic carbon (POC), charcoal (charC) and humic (hum) pools (Skjemstad and Spouncer 2002). These pools, measured in the archival soil samples, were then used to initialize the model (resistant plant matter (RPM) set to POC, inert organic matter (IOM) set to char-C, humified organic matter (HUM) set to TOC minus POC minus char-C) at the first time of sampling. Other pools were set to zero but were quickly generated by the model. It was found at both sites that adjusting the RothC default RPM pool decomposition rate modifier from 0.3 to 0.15 year $^{-1}$ rectified any divergence in the results. No other changes were necessary.

Calibration of the forestry sites was completed subsequent to the agriculture calibration and the model was tested in seven locations

- Eucalyptus globulus in the low rainfall region, south-west of Western Australia,

- E. globulus in the high rainfall region, south-west of Western Australia,

- Pinus radiata in the Green Triangle, South Australia and Victoria,

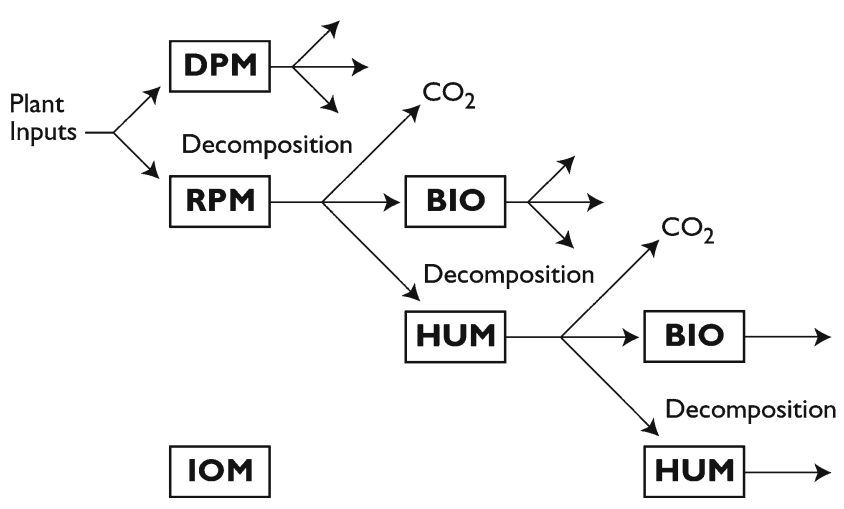

Fig. 2 Structure of the Roth-C soil carbon model as implemented in FullCAM (modified from Jenkinson 1990) 
- E. grandis in south-eastern Queensland and northeastern New South Wales,

- $P$. radiata in the south-eastern highlands, New South Wales,

- E. globulus in south-eastern Gippsland, Victoria, and

- E. nitens in the Tasmanian highlands.

The testing in the forestry sites confirmed the model calibrations for both forestry and agricultural sites.

\section{Wood products}

The NCAS has been constructed to determine national wood product stocks and changes using both top-down and bottom-up approaches (section Wood products, above). This has the advantage of enabling observation of the degree of convergence between the two input estimates, the effect of divergence, and an ability to determine, at any scale (stand to national), a wood product account.

Land cover change

\section{Deforestation}

A sequence of remotely sensed data (Landsat MSS imagery at 50-m resolution for 1972, 1977, 1980, 1985, 1988, and Landsat TM at 25-m resolution for 1989, 1991, 1992, 1995, 1998, 2000, 2002, 2004, 2005) and spatially referenced databases (including soil, vegetation, and climate maps, land-use patterns and terrain variation) were used to develop indices to discriminate between forest and non-forest cover over Australia. The location and timing of deforestation and reforestation events is determined by comparing the forest extent maps from consecutive time slices. A detailed description of the mapping and its verification can be found elsewhere (Furby 2002; Furby and Woodgate 2002; Caccetta et al. 2003; Caccetta and Chia 2004; Lowell et al. 2003; MBAC Consulting 2003; Lowell et al. 2005). The resulting disturbance maps in combination with the biomass maps and growth model enable full spatial and temporal modelling of deforestation and reforestation.

Incremental method development beyond that described by Caccetta et al. (2003) includes implementation of the terrain illumination correction $(\mathrm{Wu}$ et al. 2004) and the use of "texture"-based analysis to map the extent and change of sparse vegetation (Caccetta and Furby 2004). Mapping of tree crown cover density and the development and calibration of methods to map plantation types across Australia is ongoing, with both method refinement and field data being collected across Australia (MBAC Consulting 2006).

\section{Plantations}

Plantations are identified and mapped into three classes, native forest (environmental-type planting), hardwood plantation, and softwood plantation. Plantation forests are those identified as a result of deliberate human action, identified by type (e.g. introduction of non-endemic species), evidence of establishment practices (e.g. rip lines), planting patterns (e.g. rows, stand geometry), etc. The identification of conversion between forest and non-forest condition follows the general approach described above. Plantation classes are identified by discrimination against regionally specific collection of ground training data. The method uses an automated spectral discrimination.

\section{Managed native forests}

Identification of areas of managed native forest harvest and regrowth again uses the general mapping of forest and non-forest condition over time, with this specific activity identified by considering the temporal pattern of change, the spatial pattern of change, vegetation type, land tenure, and context.

\section{Fires}

Fire "masks" are also developed for each time epoch. This enables "mapping" of fire scars with time. These masks enable natural wildfires to be excluded from the modelling, as required.

\section{Model and data validation}

For the purposes of this section, a valid model is one in which model performance or output is satisfactory for its intended application. Implicitly, this may mean that the model form is reasonable (verified) and the numerical constants are appropriate (calibrated). This would be classified as model benchmarking by Vanclay (1994).

Forest growth

\section{Native forests}

An extensive search for data on undisturbed forest sites to enable determination of the terms in Eq. (2) found relatively few points and, consequently, no biomass data were reserved for validation. Some recent 
large-scale inventories do, however, report stand properties that can be related to biomass and hence used for model validation. In one such study the volume was estimated for over 900,000 ha of "remnant" native vegetation under private management in south eastern Queensland (MBAC Consulting 2003). Remnant vegetation was defined as areas where the predominant stratum is intact with at least $50 \%$ foliage projected cover and $70 \%$ of the height of the climax vegetation. For the purposes of this comparison the remnant vegetation could be regarded as either undisturbed or relatively lightly disturbed and, therefore, approaching the long-term aboveground biomass. An estimate of the biomass on sample plots was made using allometrics that relate above-ground biomass to stand basal area in native eucalypt forests (Snowdon et al. 2000). A regression (Eq. 6; Fig. 3) between this estimated biomass and $P$ was significant $(P<0.001$, $\left.r^{2}=0.52\right)$ with the residuals showing neither heterogeneity or non-normality (Fig. 3).

$M=(5.132 \times \sqrt{P}-6.106)^{2}$,

Although the estimated terms in Eq. (6) are not significantly different from those in Eq. (2) $(P>0.05)$, the total aboveground biomass estimated by use of Eq. (2) was significantly greater $(P>0.05)$ than the estimates derived from the inventory.

\section{Plantations}

FullCAM outputs were compared with measurements from an intensively measured $P$. radiata plantation experiment-the biology of forest growth (BFG). The BFG experiment was established in 1983 in the Australian Capital Territory (ACT) and has approximately 19 years of volume growth measurements combined with detailed site data, including aboveground biomass estimates for a period of 5 years. Data from this experiment have been used in the development and calibration of several physiological models (e.g. BIOMASS (McMurtrie et al. 1992) and CenW (Kirschbaum 1999)).

The BFG site falls near the boundary between poor and average quality soil (Eq. 1) with the broad value used in the national estate just in the latter. However, Benson et al. (1992) concluded the soil quality at BFG should be regarded as poor. FullCAM enables easy adjustment of the effects of soil quality, simply by changing classes where the broad-scale estimate is not applicable on a fine plot scale.

The biomass predictions from FullCAM (Fig. 4) follow the general growth pattern but the magnitude in the average soil prediction is consistently higher than the observed mass. This trend is also present in the volume predictions (Fig. 5) with both the average and poor soil predictions being in good agreement with the growth pattern up to 25 years and with the poor quality soil run proving particularly accurate.

As the stand ages, the difference between the volumes for the simulated poor soil and the observed values began to increase. Volume growth in the control treatment at BFG continued at an average of $19 \mathrm{~m}^{3} \mathrm{ha}^{-1}$ year $^{-1}$ from age 10 to age 29 , with only small fluctuations because of climatic conditions, and the modelled growth begins to slow by age 23 . Despite this trend, there was only approximately $10 \%$ difference between
Fig. 3 Regression of longterm productivity index $(P)$ to above ground biomass $(M)$ $\left(\mathrm{t} \mathrm{ha}^{-1}\right)$ with $90 \%$ individual confidence lines. [ ] denotes standard error of the estimates

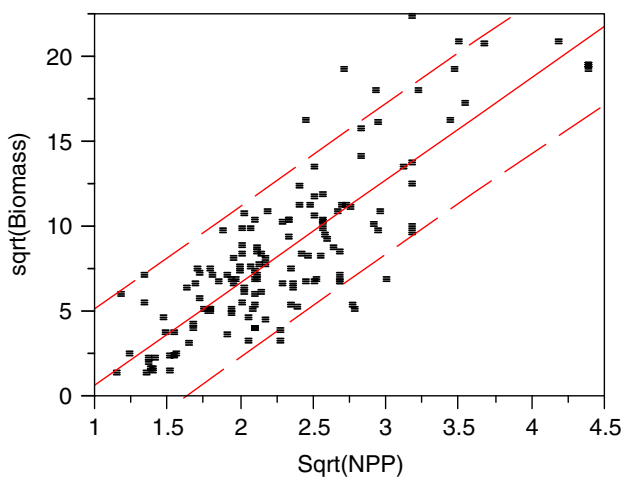

a) Biomass data provided by CSIRO and used to parameterize equation 1

$$
\begin{gathered}
M=(6.011 \times \sqrt{P}-5.291)^{2} \quad \text { Equation (2) } \\
{[0.346] \quad[0.823]}
\end{gathered}
$$

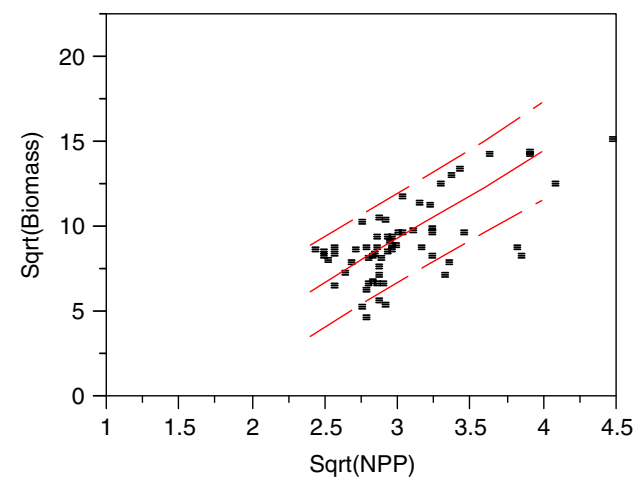

b) Biomass estimated from Snowdon et al (2000) allometrics and MBAC Consultants (2003) inventory data

$$
\begin{gathered}
\widehat{M}=(5.132 \times \sqrt{P}-6.106)^{2} \quad \text { Equation (6) } \\
{[0.667] \quad[1.981]}
\end{gathered}
$$




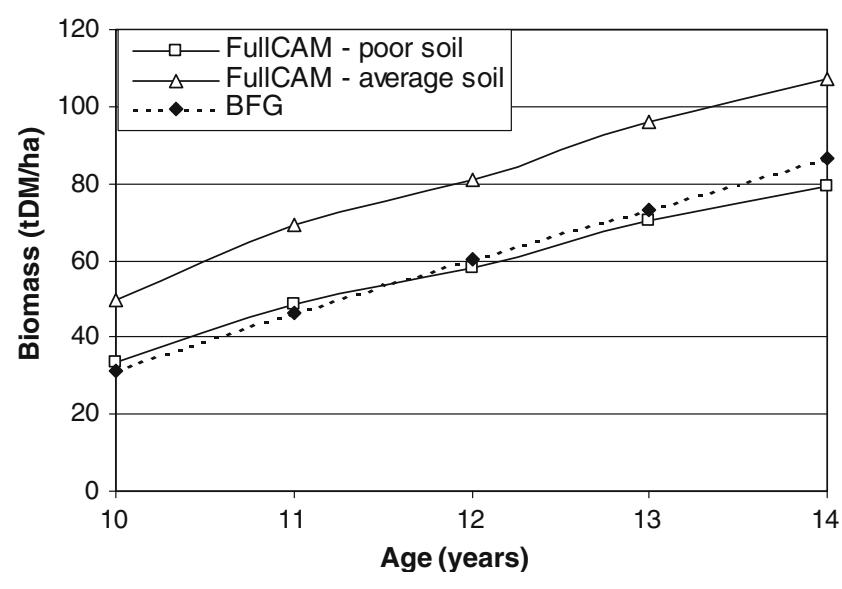

Fig. 4 Aboveground biomass at BFG (control) compared with FullCAM estimates assuming poor and average soils

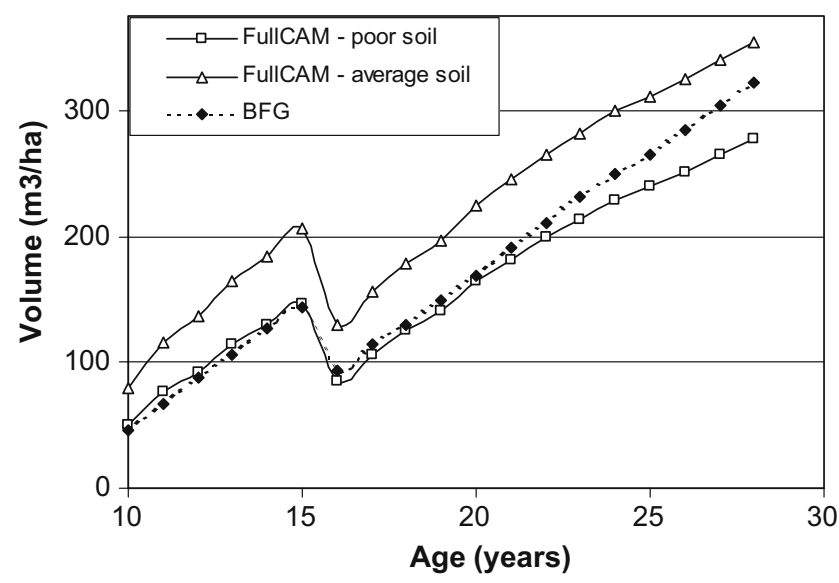

Fig. 5 Stem volume in the BFG experiment (control) compared with FullCAM estimates assuming poor and average soils

the actual and modelled values (average or poor) at age 29. Importantly, the increments over time periods are very similar, even though the absolute values can be quite different. The age structure of the national plantation estate will therefore minimise potential error over short time periods. Because volume is back predicted by FullCAM from aboveground biomass, the volume differences may simply be a function of the variable density function used (Polglase et al. 2004) or differences in allocation rather than actual differences in the aboveground biomass predictions.

\section{Soils}

Validation of the NCAS soil-carbon model used a combination of comparison with results from timeseries measurements at research sites (independent of those used for model calibration) and paired site sampling. The results of the validation activity are re- ported elsewhere (Skjemstad and Spouncer 2002; Paul et al. 2003). The validation results were usually good, with (fortuitously) best model performance in areas of most significant land-use change. Overall, the model agreement with research site data was better than with the paired sites. Further investigation led to the conclusion that the paired sites were located on soils for which the model has weaknesses, but also that there was more imprecision for the paired sites because of soil variability and site histories different from those expected.

Coarse woody debris and litter

Given the complex and dynamic nature of this pool, it was concluded that verification could not rely on measurement of inputs, transitions, and losses due to disturbance. Instead, the mass-balance cycling model approach was used to determine the quality of model calibration. Given inappropriate or poorly calibrated input, transfer and losses, the principal of mass balance meant the model would, over a long period of time, predict inappropriate pool size (too large or too small in this or surrounding pools). Estimates of coarse woody debris were made on the basis of the literature and field studies to frame the initial model estimates that reflect typical conditions.

Wood products

The eventual constraining and convergence of top-down and bottom-up approaches for estimating harvested wood products will provide confidence in estimates of inputs of materials. Studies such as those by Ximenes and Gardner (2005) and Ximenes et al. (2005) can also selectively validate different aspects of the model. For other aspects of data used in the model, significant further work will be required to reduce uncertainty in model estimates. These data include refined estimates of the service life of wood-containing products, rates of recycling and use in new products, and disposal by landfill or incineration. Further work is being conducted on rates of turnover and the nature of the gas emitted during decomposition in landfill.

\section{Land cover change}

The validation of remotely sensed changes in forest cover is contained within an overall continuous improvement and validation program. The initial validation (Lowell et al. 2003, 2005) considered the initial time-series of change data from 1972 to 2000. This was done by comparison of air photographs. Results from 
this work then guided improvements made when the time-series was updated, with 2002 data, and the full time-series re-analysed to reflect the improvements. Similar updates were also undertaken for 2004 and 2005. Validation of analyses, both for changes in forest cover and for changes in sparse woody vegetation used comparisons with very high-resolution data; this substantially improved the quality of the validation. Previously the air photographs, even when using resolution of 1:25,000 were inconclusive as a validation dataset.

An independent analysis of the "raw" accuracy of the classification of woody and non-woody points across the continent and over the period 1972-2000 indicated that $2-6 \%$ of forest and $4-15 \%$ of non-forest was incorrectly classified (Jones et al. 2004). Errors in the estimated rates of change (afforestation/regrowth or deforestation), however, were lower than the above errors because a process of manual "attribution" was used to confirm or reject changes in cover in the final dataset. Forms of error removed are those associated with green flushing in imagery, degradation, terrain illumination, irrigation, water bodies, and fire scars.

Validation of plantation type mapping accuracy was performed against field data specifically collected to identify plantation species and to assess stocking, condition, age, and extent. These validation data were collected during a national program of site visits. The recently completed plantation mapping achieved an accuracy of $91 \%$ in terms of both species and spatial referencing for plantations identified as post-1990 plantations (MBAC Consulting 2006). Incorrect forest typing (e.g. labelling hardwood as softwood and visa versa) contributed $5 \%$ of the error, with only $4 \%$ being incorrect by both location and type. These results inspire substantial confidence in the methodology applied and enable, for the first time, spatio-temporal analysis of Australia's plantations.

Deforestation is defined as occurring when forest is deliberately removed for the purpose of a change in land use. Regrowth is when, either deliberately or naturally, a forest regrows on an area previously deforested. Deforestation is spatially separated (and unique) from natural effects such as dieback and fire, and temporary removals of forest by harvest. The permanent or temporary nature of the change is determined by visual checking of the time-series data.

\section{The nitrogen model}

The carbon cycling approaches used in the FullCAM model are similar to those implemented in the Century model (Parton et al. 1987), which enabled FullCAM to be further developed to include nitrogen cycling, using the Century approach as a basis. Inclusion of nitrogen cycling serves two functions. The first is to constrain growth where there is insufficient nitrogen available to plants to support that growth. This is often particularly important in Australian conditions. The second is to estimate the amount of nitrogen volatilised, or lost to nitrification and denitrification. These estimates are of specific interest, because losses of $\mathrm{N}_{2} \mathrm{O}$ to the atmosphere are required when reporting greenhouse gas emissions. The model couples nitrogen cycling with the boundary line approach (Conen et al. 2000) and uses estimated nitrogen available, set temperatures, and water-filled pore space to determine $\mathrm{N}_{2} \mathrm{O}$ emissions.

Calibrations of the nitrogen model component of FullCAM have been developed for one cropping and one plantation site. Sites with sufficient time-series data for calibration of both carbon and nitrogen are very scarce. Unfortunately, no site with a sufficiently long time-series description of carbon and nitrogen cycling has also measured actual emissions. To supplement the sparse emissions data available, a series of intact soil cores have been treated in different ways in laboratory incubations. Such incubation enables identification of thresholds for denitrification and of the quantity of emissions during denitrification. In concert with a series of in-situ field chambers, sufficient data should be available for model calibration and validation.

Calibration of the model has revealed several issues that must be considered. The first is that because turnover is faster and behaviour more volatile (episodic) for nitrogen cycling than for carbon cycling, a daily time-series is required for model runs. The model is also very sensitive to plant uptake and, in forest systems, to storage in plant biomass.

\section{Discussion}

A key strength of the NCAS is its comprehensive treatment of both carbon and nitrogen cycles covering all terrestrial pools and processes so that:

- mass balances of carbon and nitrogen are achieved with interactions between terrestrial and atmospheric stores; and

- the interplay and effect on biological processes of carbon and nitrogen cycles (e.g. growth limited by nitrogen depletion; decomposition limited by substrate availability) are acknowledged.

By taking mass-balance approaches, and being comprehensive of all relevant land-based activity, the 
NCAS ensures that no gaps or overlaps occur in estimates of greenhouse gas emissions.

The decision to implement the comprehensive and integrated form of NCAS was based on the development of a critical mass of resource information and significant core capabilities that have broad applications. The most significant of these are the 14 Landsat MSS (1972-1988) and TM/ETM ${ }^{+}$(1988-2005) coverages of Australia. The pixel resolution of the data is $50 \mathrm{~m}$ for MSS and $25 \mathrm{~m}$ for TM/ETM (Furby 2002). Another core product was interpolated monthly climate maps of Australia for rainfall, evaporation, minimum, maximum, and average temperature, and number of frost days per month. Slope and aspectcorrected $250-\mathrm{m}$ resolution solar radiation measurements, direct and diffuse, were also developed (Landsberg and Kesteven 2001; Kesteven et al. 2004). Together, these products provide a dynamic background to the modelling activities of the NCAS.

Compiling the necessary fundamental and derivative data also encouraged broad strategic relationships to evolve with other natural resource management interests in areas such as vegetation management, forest inventory, soil organic matter management, resource economics etc. The development of the NCAS has thus involved scientists from numerous different disciplinary backgrounds, bringing together their expert knowledge. Forest scientists, agricultural scientists, soil scientists, statisticians, remote sensing experts, climatologists, modellers, and specialist programmers were involved. These broader interests facilitate exchanges of data and knowledge that improve system efficiency and effectiveness.

Another important consequence of coordinated approaches is the possibility of encouraging systematic and continuous improvement and validation activity. The flexibility of the modelling approach enables the model to be re-calibrated or new components to be relatively easily integrated; this again optimises the functional outputs derived from dedication of public resources to this activity. Most of the input data are related to climate on a fine temporal scale, because this variability has a significant effect on many of the biological processes of growth and decay. Another substantial set of data is related to possible management activity and disturbance events and how these would affect the basic processes.

Use of a hybrid process-driven and empirical approach has resulted in a robust generalized method for determining forest biomass stocks and rates of forest growth for Australia. Equation (1) enables appreciation of the processes underpinning growth and Eqs. (2)-(5) enable these process-based relationships to be grounded in empirical observations. Consequently the agreement between the patterns of observed biomass and FullCAM predictions (Figs. 3, 4, and 5) was not unexpected.

The regression approach has an advantage over a purely process-driven model which has been shown to usually over-predict site biomass, because factors such as insect attack are not taken into account (Kurz et al. 1998). The potential biomass estimate in FullCAM is the maximum biomass towards which growth will usually approach. It may be that overprediction of biomass in Queensland's privately managed forests (Fig. 1) is a consequence of this process-model bias; it is, however, more likely to be because of localised bias with the Snowdon et al. (2000) allometrics or because the stands had been disturbed and were still returning to the long-term maximum state.

By taking mass-balance approaches, and being comprehensive of all relevant land-based activities, the NCAS ensures that no gaps or overlaps occur in the estimates of greenhouse gas emissions.

Although currently limited to use for carbon accounting, the FullCAM outputs have great potential for estimating other statistics of interest to the forest industry and other land managers. For example, any variable related to above ground biomass (or other output produced by FullCAM) can be more precisely estimated by use of an inventory system using the point estimates output by FullCAM as auxiliary variables in a variable-probability inventory. For example, Brack (2004) found that the presence of an auxiliary variable with an $r^{2}$ value similar to that found in Eq. (6) could be used in an appropriate inventory design to improve the precision of the population estimates by a factor of two compared with that of a systematic sampling system.

The quality of the land cover change modelling (section Land cover change, above) suggests it has great potential for estimating other statistics of interest, for example total areas by type and areas harvested. The spatially explicit time-series of vegetation cover change enables understanding of where and when change has or is occurring. Coupled with ancillary information this can be used to identify pressures on different types of vegetation. Examples include the spread of weed species, loss of species or communities of interest, states of riparian vegetation, or connectivity for wildlife habitat and movement. By coupling forest growth and stocks estimates with the age and forest type drawn from the remote sensing estimates it is also possible to determine future wood flow estimates from the current forest estate. 
An often-expressed criticism of such strongly coordinated programs is that they stifle the innovation that can be derived from scientific competition. To reduce the potential for this to occur the development of the FullCAM model has retained a flexible approach to new ideas and techniques. Because the end product must be capable of robust national operation, however, conservatism in adoption of emergent ideas and technologies has been applied.

\section{National carbon accounting toolbox and DataViewer}

As part of the NCAS program a public release version of FullCAM combined with electronic copies of the technical report series and Landsat imagery (the DataViewer) has been made available. This is a valuable resource for land managers while ensuring greater transparency of the NCAS.

The DataViewer contains five of the fourteen national composite Landsat satellite sensor images (1972, 1980, 1989, 2000, 2004) obtained and registered by the NCAS, continental maps of long-term average rainfall, minimum, average, and maximum temperatures, evaporation, and number of frost days. Recent improvements in image compression technology enabled all of these data to fit on a one DVD. The associated program enables users to locate and zoom into any area of Australia and compare images to help determine changes in land use from 1972 to 2004. All of these images can be easily imported into more complex GIS systems.

Although a useful tool, the image compression used in the DataViewer does lead to some reduction in visual quality. The archive of Landsat data has been made publicly available through Geoscience Australia (http://www.ga.gov.au) for the cost of data transfer. This is a major improvement in the availability of landuse data for land managers in Australia.

The NCAT contains a public release version of FullCAM and all of the NCAS Technical Reports which summarize how and why the system was established, data used in the development of the system, and the results of continental simulations. The public release version does not contain nitrogen-cycle modelling capabilities or other model aspects currently under development or restricted to research use.

As part of the NCAT development, FullCAM was fitted with a Databuilder function. A single FullCAM plot file typically requires over 1,500 inputs, including monthly climate records and species and management information making it difficult and time-consuming to develop a single model. The Databuilder function simplifies this process by downloading all the required data for a point from a webserver that contains all the climate, species and management data as used in NCAS continental simulations. Users simply select the type of system they wish to model (forest only, agriculture only, or transitions between the two), enter a latitude and longitude (obtainable from the Dataviewer) and click a button to download the spatial data. The model then accesses the webserver and obtains the required climate and site information for the specific location from either $250 \mathrm{~m}$ or $1 \mathrm{~km}$ grids depending on the data type. Users then further decide what species and management actions they wish to model and further download the required data from the server. Hence users can quickly build a FullCAM plot using the best available data at the national level within 2 min. These models can then be saved, shared with other users, and run at any time without a web connection. Because the full model is provided, advanced users can also adjust any variable in the model to better fit their exact circumstances.

The provision of the Landsat imagery through the Dataviewer and Geoscience Australia, and the ability to download over 30 years of monthly climate records free of charge provides researchers, land managers, and policy makers with readily accessible, nationally consistent, site-specific information for the first time.

\section{Conclusion}

The development of Australia's National Carbon Accounting System (NCAS) has been highly planned; it is systematic and integrated. The approach includes all pools and lands, which minimises the chance of errors of omission or commission that beset many national inventories. Extensive and independent testing has validated the model, showing it to be satisfactory for its purposes of national account modelling, providing information for policy development, and supporting management on a regional scale.

Activity has been planned around technical and functional goals to meet key policy, emissions reporting, and analysis needs. The FullCAM model, as the model used by the NCAS, has been able to focus relevant data-collection and model calibration activity. Importance and sensitivity analysis using FullCAM has been used to guide priorities for data collection and biological process studies and to ensure that outputs of support activities are directly relevant to emissions reporting and analysis needs. 
By providing the framework for different data collection and process studies, guided by importance and sensitivity analyses, FullCAM has optimised the efficiency and relevance of supporting studies.

Although the system was developed primarily for carbon accounting, the continental nature and variety of data sources developed and collated enable application across a wide range of other natural resourcemanagement systems.

By implementing an integrated system, sensitivity analysis can be used to strategically guide the potential impact of improvements. Ongoing validation programs feed the information needed for both uncertainty analysis and continuous improvement.

\section{References}

AUSLIG (2001) Digital Elevation Model of Australia Version 2.0., Canberra, Australia

Benson ML, Landsberg JJ, Borough CJ (1992) The biology of forest growth experiment: an introduction. For Ecol Manage 52:1-16

Brack C (2004) Projecting native forest inventory estimates from public to private tenures. Aust For 67:230-235

Caccetta P, Chia J (2004) Remote sensing methods for plantation attribution-experiments and results for Mapsheet Si50. CSIRO Mathematical and Information Sciences

Caccetta P, Furby S (2004) Monitoring sparse perennial vegetation cover. In: The 12th Australasian remote sensing and photogrammetry conference proceedings, Fremantle, Western Australia, 18-22 October

Caccetta PA, Bryant G, Campbell NA, Chia J, Furby S, Kiiven HJ, Richards GP, Wallace J, Wu X (2003) Notes on mapping and monitoring forest change in Australia using remote sensing and other data. In: 30th international symposium of remote sensing and the environment, Hawaii, October 2003

Conen F, Dobbie KE, Smith KA (2000) Predicting $\mathrm{N}_{2} \mathrm{O}$ emissions from agricultural land through related soil parameters. Global Change Biol 6:417-426

Furby S (2002) Land cover change: specification for remote sensing analysis. National Carbon Accounting System Technical Report 9, Australian Greenhouse Office, p 411

Furby S, Woodgate P (2002) Remote sensing analysis of land cover change: pilot testing of techniques. National Carbon Accounting System Technical Report 16, Australian Greenhouse Office, p 372

Griffin EA, Verboom WH, Allen D (2002) Paired site sampling for soil carbon estimation-WA. National Carbon Accounting System Technical Report No.38, Australian Greenhouse Office, Canberra

Harms B, Dalal R (2002) Paired site sampling for soil carbon estimation-QLD. National Carbon Accounting System Technical Report No. 37, Australian Greenhouse Office, Canberra

IPCC (2001) Climate Change 2001: synthesis report. In: Watson RT, The Core Writing Team (eds) A contribution of working groups I, II and III to the third assessment report of the intergovernmental panel on climate change. Cambridge University Press, Cambridge
Jaakko Pöyry consulting (1999) Usage and life cycle of wood products. National Carbon Accounting System Technical Report No. 8, Australian Greenhouse Office, Canberra, Australia, p 88

Jaakko Pöyry consulting (2000) Analysis of wood product accounting options for the National Carbon Accounting System. National Carbon Accounting System Technical Report No. 24, Australian Greenhouse Office, Canberra, Australia, p 36

Jenkinson DS (1990) The turnover of organic carbon and nitrogen in soil. Philos Trans R Soc B 329:361-368

Jones S, Lowell KE, Woodgate P, Buxton L, Mager A, Liebchen S (2004) Update on the national carbon accounting system continuous improvement and verification methodology. National Carbon Accounting System Technical Report 46, Australian Greenhouse Office, Canberra

Kesteven J, Landsberg J, URS Consulting (2004) Developing a national forest productivity model. National Carbon Accounting System Technical Report No.23, Australian Greenhouse Office, Canberra

Kirschbaum MUF (1999) CenW, a forest growth model with linked carbon, energy, nutrient and water cycles. Ecol Model 118:17-59

Kurz WA, Beukema SJ, Apps MJ (1998) Carbon budget implications of the transition from natural to managed disturbance regimes in forest landscapes. Mitig Adapt Strat Global Change 2:405-421

Landsberg JJ, Kesteven J (2001) Spatial estimation of plant productivity. In: Richards G (ed) National Carbon Accounting System Technical Report No. 27. Australian Greenhouse Office, Canberra, pp 33-50, chap 2

Landsberg JJ, Waring RH (1997) A generalised model of forest productivity using simplified concepts of radiation-use efficiency, carbon balance and partitioning. For Ecol Manage 95:209-228

Lowell KE, Richards GP, Woodgate P, Jones S, Buxton L (2005) Fuzzy Reliability assessment of multi-period land-cover change maps. Photogramm Eng Remote Sens 71:939-945

Lowell KE, Woodgate P, Jones S, Richards GP (2003) Continuous improvement of the national carbon accounting system land cover change mapping. National Carbon Accounting System Technical Report 39, Australian Greenhouse Office, p 36

Lund GH, Iremonger S (2000) Omissions, commissions, and decisions: the need for integrated resource assessments. For Ecol Manage 128:3-10

MBAC Consulting (2003) South East Queensland Private Native Forest Inventory. BRS publications, Canberra, Australia, p 161

MBAC Consulting (2006) CSIRO Plantation Imagery Verification. Australian Greenhouse Office, Canberra, Australia (in preparation)

McKenzie NJ, Jacquier DW, Ashton LJ, Cresswell HP (2000) Estimation of soil properties using the Atlas of Australian Soils. CSIRO Land and Water Technical Report 11/00

McMurtrie RE, Leuning R, Thompson WA, Wheeler AM (1992) A model of canopy photosynthesis and water-use incorporating a mechanistic formulation of leaf $\mathrm{CO}_{2}$ exchange. For Ecol Manage 52:261-278

Mohren F, Goldewik KK (1990) $\mathrm{CO}_{2}$ Fix. De Dorrchamp, Wageningen

Moorehead DL, Reynolds JF (1991) A general model of litter decomposition in the Northern Chihuahuan Desert. Ecol Model 59:197-219 
Murphy B, Rawson A, Ravenscroft L, Rankin M, Millard R (2002) Paired site sampling for soil carbon estimation-NSW. National Carbon Accounting System Technical Report No. 34-Pre-publication draft, Australian Greenhouse Office, Canberra

NLWRA (2001) Australian native vegetation assessment. National Land and Water Resources Audit, Canberra

Parton WJ, Schimel DS, Cole CV, Ojima DS (1987) Analysis of factors controlling soil organic matter levels in Great Plains grasslands. Soil Sci Soc Am J 51:1173-1179

Paul KI, Polglase PJ, Nyakuengama JG, Khanna PK (2002) Change in soil carbon following afforestation. For Ecol Manage 168:241-257

Paul KI, Polglase PJ, Richards GP (2003) Sensitivity analysis of predicted change in soil carbon following afforestation. Ecol Model 164:137-152

Polglase PJ, Snowdon P, Theiveyanathan T, Paul KI, Raison RJ, Grove T, Rance SJ (2004) Calibration of the FullCAM model to Eucalyptus globulus and Pinus radiata and uncertainty analysis. Nation Carbon Accounting System Technical Report No. 40, Australian Greenhouse Office, Canberra

Raison RJ, Keith H, Barrett D, Burrows W, Grierson PF (2003) Spatial estimates of biomass in 'Mature' native vegetation. National Carbon Accounting System Technical Report 44, Australian Greenhouse Office, Canberra, Australia, p 56

Richards G, Brack C (2004) A continental biomass stock and stock change estimation approach for Australia. Aust For 67:284-288

Richards G, Evans D (2004) Development of a carbon accounting model (FullCAM Vers. 1.0) for the Australian continent. Aust For 67:277-283

Richards GP (2001) The FullCAM carbon accounting model: development, calibration and implementation for the national carbon accounting system. National Carbon Accounting System Technical Report 28, Australian Greenhouse Office, Canberra, p 60

Richards GP, Evans DMW (2000a) Carbon accounting model for forests (CAMFor) user manual version 3.35. National Carbon Accounting System Technical Report 26. Australian Greenhouse Office, Canberra, p 64

Richards GP, Evans DMW (2000b) Carbon accounting model for agricultural systems. Australian Greenhouse Office, Canberra

Sands PJ, Landsberg JJ (2002) Parameterisation of 3-PG for plantation grown Eucalyptus globulus. For Ecol Manage 163:273-292

Schlamadinger B, Canella L, Marland G, Spitzer J (1997) Bioenergy strategies and the global carbon cycle. Sci Geologiques 50:157-182
Skjemstad J, Spouncer L (2002) Estimating changes in soil carbon resulting from changes in land use. National Carbon Accounting System Technical Report No. 36, Australian Greenhouse Office, Canberra

Skjemstad J, Spouncer L, Beech TA (2000) Carbon conversion factors for historical soil carbon data. National Carbon Accounting System Technical Report No. 15. Australian Greenhouse Office, Canberra, p 17

Snowdon P (2002) Modeling type 1 and type 2 growth responses in plantations after application of fertilizer or other silvicultural treatments. For Ecol Manage 163:229-244

Snowdon P, Eamus D, Gibbons P, Khanna PK, Keith H, Raison RJ, Kirschbaum MUF (2000) Synthesis of allometrics, review of root biomass and design of future woody biomass sampling strategies. National Carbon Accounting System Technical Report No. 17, Australian Greenhouse Office, Canberra, Australia

Squire R, Raison RJ (2006) Forest management in Australia: implications for carbon budgets. National Carbon Accounting System Technical Report No 32, Australian Greenhouse Office, Canberra (in press)

Swift R, Skjemstad J (2002) Agricultural land use and management. National Carbon Accounting System Technical Report 13, Australian Greenhouse Office, Canberra

Thackway R, Cresswell IDe (1995) An interim biogeographic regionalisation for Australia: a framework for establishing the natural system for reserves, Version 4.0. Australian Nature Conservation Agency, Canberra

Vanclay JK (1994) Modelling forest growth and yield: applications to mixed tropical forests. CAB International, Wallingford

Webbnet Land Resource Services Pty Ltd (2002) Pre-clearing soil carbon levels in Australia. National Carbon Accounting System Technical Report No. 12, Australian Greenhouse Office, Canberra

Wu X, Furby S, Wallace J (2004) An approach for terrain illumination correction. In: The 12th Australasian remote sensing and photogrammetry conference proceedings, Fremantle, Western Australia, 18-22 October

Ximenes F, Gardner D (2005) Recovery of biomass as green sawn boards after milling of Spotted Gum (Corymbia maculata) Sawlongs from NSW South Coast Forests. National Carbon Accounting System Technical Report No. 48, Australian Greenhouse Office, Canberra

Ximenes F, Gardner D, Marchant J (2005) Total biomass measurement and recovery of biomass in log products in Spotted Gum (Corymbia maculata) forests of SE NSW. National Carbon Accounting System Technical Report No. 47, Australian Greenhouse Office, Canberra 